\title{
Hyperacute versus Subacute Coiling of Aneurysmal Subarachnoid Hemorrhage a Short-term Outcome and Single-Center Experience, Pilot Study
}

\author{
Abdulrahman Mostafa Ibrahim Ali ${ }^{*}$, Ghada Abdel Hady Ossman Ashmawy', \\ Ayman Youssef Ezeddin Eassa ${ }^{1}$ and Osama Yassin Mansour ${ }^{1,2}$ \\ 'Department of Neurology and Psychiatry, Faculty of Medicine, University of Alexandria, Alexandria, Egypt, \\ ${ }^{2}$ Stroke Center, Alexandria University Hospital, Alexandria, Egypt
}

\section{OPEN ACCESS}

Edited by:

Shakir Husain Hakim,

Stroke and Neurointervention

Foundation, India

Reviewed by:

Ferdinando S. Buonanno, Massachusetts General Hospital,

Elias A. Giraldo,

University of Central Florida College of Medicine, USA

${ }^{*}$ Correspondence: Abdulrahman Mostafa Ibrahim Ali abdulrahman.mostafa@yahoo.com

Specialty section: This article was submitted to Endovascular and Interventional Neurology, a section of the journal

Frontiers in Neurology

Received: 01 October 2014 Accepted: 02 May 2016

Published: 16 June 2016

Citation:

Ibrahim Ali AM, Ashmawy GAHO,

Eassa AYE and Mansour OY (2016) Hyperacute versus Subacute Coiling of Aneurysmal Subarachnoid Hemorrhage a Short-term Outcome and Single-Center Experience, Pilot Study.

Front. Neurol. 7:79.

doi: 10.3389/fneur.2016.00079
Background: After the initial subarachnoid hemorrhage (SAH), rebleeding is the major cause of morbidity and poor outcome, which is maximal in the first $24 \mathrm{~h}$. We supposed that the coiling of ruptured intracranial aneurysms within $24 \mathrm{~h}$ of SAH is related to the improved clinical outcome compared with coiling $24 \mathrm{~h}$ after aneurysmal SAH.

Objective: We examined whether coiling ruptured aneurysms within $24 \mathrm{~h}$ of aneurysmal $\mathrm{SAH}$ is associated with better early $24 \mathrm{~h}$ and late 30 days outcome.

Method: This prospective study was carried on 30 patients with aneurysmal SAH presenting to the Alexandria University Hospital and Insurance Main Hospital during the period from February 2013 to May 2014. They were divided into two groups: Group I (10 patients treated within $24 \mathrm{~h}$ of presentation) and Group II (20 patients treated after $24 \mathrm{~h}$ of presentation). Time interval from presentation to treatment were 78.60 and $10.60 \mathrm{~h}$ for subacute and hyperacute group, respectively. All patients were treated with endovascular coiling. Change between admission and immediate postoperative World Federation of Neurosurgeons classification Scale was measured for early outcome, while remote outcome was measured by modified Rankin Scale at 30 days follow-up.

Results: There was a clinical improvement regarding early $24 \mathrm{~h}$ outcome (weighted by postoperative WFNS grade) and on late 30 days outcome (weighted by Modified Rankin Scale Score) in the group managed within $24 \mathrm{~h}$ versus who were treated after $24 \mathrm{~h}(P=0.049$ and $P=0.024$, respectively). There was a significant decrease in the incidence of clinical rebleeding detected by postoperative computed tomography (CT) of the brain in patients undergoing aneurysm treatment within $24 \mathrm{~h}(P=0.029)$.

Conclusion: The study affirms evidence that the management of ruptured intracranial aneurysms within $24 \mathrm{~h}$ of $\mathrm{SAH}$ is associated with better immediate and short-term clinical outcome.

Keywords: subarachnoid hemorrhage, endovascular treatment, aneurysm, timing, outcome

Abbreviations: SAH, subarachnoid hemorrhage; WFNS, World Federation of Neurosurgeons classification Scale. 


\section{INTRODUCTION}

Aneurysmal subarachnoid hemorrhage (SAH) is a subset of stroke that occurs at a relatively young age (median 55 years) and has a high rate of morbidity (25\%) and case fatality (35\%). In SAH patients who survive the first few days after bleeding, rebleeding is an important contributor to poor outcome (1).

For the last two decades, there has been proof that most rebleeds occur during the first $24 \mathrm{~h}$ after SAH. Multiple studies have proven that the incidence of rebleeding is maximal during the first $24 \mathrm{~h}$ after SAH with rates of $4.1-17.3 \%$ reported (2). Most studies reporting outcomes associated with rebleeding within $24 \mathrm{~h}$ have demonstrated case-fatality rates approaching $65 \%$, some as high as $80 \%$, and incidences of $10 \%$ (3).

The time interval from presentation to management of acutely ruptured aneurysms (endovascular coiling) has been the issue of considerable debate (2). Earlier treatment of the ruptured intracranial aneurysm is associated with the lower incidence of rebleeding but was historically considered as a higher risk than a delayed management (4).

Few studies analyzed the management of ruptured aneurysms within $24 \mathrm{~h}$ of SAH, most of them were in retrospective manner not prospective one like our study (5). Also, most of them were comparing any intervention (both surgery and endovascular coiling) in addition to defining early treatment at the first $72 \mathrm{~h}$ after $\mathrm{SAH}$, unlike our study. To date, not enough published data are present that compare hyperacute treatment (within $24 \mathrm{~h}$ of aneurysmal SAH) with treatment at more than $24 \mathrm{~h}$ post-SAH (6). We believe that our work is somewhat novel.

We supposed that coiling of ruptured intracranial aneurysms within $24 \mathrm{~h}$ of SAH is related to improved clinical outcome compared with coiling $24 \mathrm{~h}$ after aneurysmal SAH.

\section{MATERIALS AND METHODS}

\section{Subject}

This study was carried out among patients with SAH presenting to the Alexandria University Hospital and Insurance Main Hospital during the period from February 2013 to May 2014. The study consisted of 30 patients with aneurysmal SAH divided into two groups: Group I: study group (10 patients); hyperacute aneurysmal SAH referred for coiling and treated within $24 \mathrm{~h}$ from presentation and Group II: study group (20 patients); subacute aneurysmal SAH referred for coiling and treated after $24 \mathrm{~h}$ from presentation. All patients underwent clinical evaluation that include personal data, medical data, past medical history, social history, and complete clinical neurological examination. Early $24 \mathrm{~h}$ outcome was measured by World Federation of Neurosurgeons classification Scale (7) at $24 \mathrm{~h}$ postoperatively, and late 30 days outcome was measured by the modified Rankin Scale at 30 days follow-up by contacting the participants by telephone and arranging an interview (8). Rebleeding was detected by an increase of Fisher grade through evidence of blood in the subarachnoid space, ventricular system, or brain parenchyma by follow-up computed tomography (CT). Rebleeding may be symptomatic [associated with acute clinical deterioration (decrease of one or more grade on Glasgow Coma Score) and confirmed by repetitive CT scan] or asymptomatic [confirmed by repetitive CT scan only]. Pre endovascular evaluation included CT of the brain, CT angiography, and initial diagnostic subtraction angiography (DSA). All the ethical committee data and request are included, including the consent from all patients.

\section{Procedure}

The endovascular treatment was started by puncture of the femoral artery, followed by introducing the guide-catheter $(6 \mathrm{~F})$ to be positioned in the cervical vessel that allows access to the aneurysm. Angiographic assessment by a rotational angiographic data set to obtain 3D reconstruction of the aneurysm. We started with possible largest coil then smaller one and so on, under fluoroscopic roadmap guidance, to serves framing the theoretical boundary of the aneurysm (framing coil). Appropriately sized smaller coils were subsequently delivered to fill the aneurysm fundus, anticoagulation with intravenous heparin, or heparinization during treatment was employed. In some cases, we used simple coiling while in other cases where simple coiling is impossible, we used adjunctive endovascular maneuvers (assisted coiling) that involve the one of the following:

a. Remodeling of the neck (neck selective technique), in case of wide neck, such as:

i. Balloon-assisted coiling

ii. Stent-assisted coiling

b. Remodeling of the sac (branch selective technique), such as catheter-assisted catheter technique.

Endovascular treatment to all patients and validation of data in terms of angiographic findings and treatment efficacy were done by consultant neuro-interventionist, Osama Yassin Mansour. Outcome assessment was done by the corresponding author and reviewed by the other two authors.

\section{Postoperative Management}

The treatment of vasospasm was managed by Triple-H therapy (induced hypertension, hypervolemia, and hemodilution) and endoluminal angioplasty. Post-endovascular evaluation included postoperative $\mathrm{CT}$ of the brain to exclude any postoperative complications (intra-cerebral and/or intra-ventricular hemorrhage, brain oedema, or cerebral infarction).

Our policy is to manage all cases within $24 \mathrm{~h}$ of aneurysmal SAH. Management delays were due to the transfer from other hospitals or from rural areas, hospital logistical delays (access to operating rooms and nursing staff), and delayed diagnoses.

The study protocol was reviewed and approved by data safety monitoring board and subsequently by the local institutional review board. Each patient or his relative signed a written informed consent before the procedure. Relevant data were recorded on a standard case reporting form.

Data were fed to the computer and analyzed using IBM SPSS software package version 20.0. The distributions of quantitative 
variables were tested for normality using Kolmogorov-ShapiroWilk test and D'Agstino test, also Histogram and QQ plot were used for vision test. For normally distributed data, comparison between two independent populations was done using independent $t$-test. Significance of the obtained results was judged at the $5 \%$ level.

\section{RESULTS}

Statistical analysis demonstrated no significant difference in age, gender, hypertension, diabetes mellitus, admission grade, size, and location between those managed within $24 \mathrm{~h}$ (hyperacute) and those managed after $24 \mathrm{~h}$ (subacute). We had only one patient who died during the follow-up in the subacute group (Table 1).

Early $24 \mathrm{~h}$ outcome was measured by clinical improvement weighted by reduction in WFNS grade ( $\geq 1$ grade). In the hyperacute group,; there were eight patients $(80 \%)$ who were clinically improved, compared to six patients $(30 \%)$ in the subacute group with statistical significant difference between both groups $(P=0.019)$ (Table 2).

Dichotomization of the $\mathrm{mRS}$ outcome data into good outcome (mRS 0-2) and high morbidity (mRS 3-5) also demonstrated a

TABLE 1 | Comparison between the two studied groups as regards demographic data and risk factors.

\begin{tabular}{|c|c|c|c|}
\hline & $\begin{array}{l}\text { Subacute group } \\
\text { (after } 24 \text { h, } \\
20 \text { patients) }\end{array}$ & $\begin{array}{l}\text { Hyperacute group } \\
\text { (within } 24 \mathrm{~h}, \\
10 \text { patients) }\end{array}$ & $P$ value \\
\hline Age & $50.65 \pm 12.40$ & $50.50 \pm 15.81$ & 0.977 \\
\hline Female & $12(60)$ & $3(30)$ & 0.121 \\
\hline $\mathrm{HTN}$ & $13(65)$ & $7(70)$ & 1.000 \\
\hline DM & $4(20)$ & $3(30)$ & 0.657 \\
\hline $\begin{array}{l}\text { WFNS grade (admission } \\
\text { grade) }\end{array}$ & & & 0.313 \\
\hline 1 & $9(45)$ & $2(20)$ & \\
\hline 2 & $5(25)$ & $4(40)$ & \\
\hline 3 & $3(15)$ & $4(40)$ & \\
\hline 4 & $2(10)$ & $0(0)$ & \\
\hline 5 & $1(5)$ & $0(0)$ & \\
\hline Mortality & $1(5)$ & $0(0)$ & \\
\hline Size (mm) & & & 1.000 \\
\hline Less than 7 & $11(55)$ & $6(60)$ & \\
\hline $7-12$ & $8(40)$ & $4(40)$ & \\
\hline $13-24$ & $1(5)$ & $0(0)$ & \\
\hline More than 25 & $0(0)$ & $0(0)$ & \\
\hline Location & & & 1.000 \\
\hline Anterior circulation & $14(70)$ & $7(70)$ & \\
\hline ICA & $3(15)$ & $1(10)$ & \\
\hline ACOM & $6(30)$ & $5(50)$ & \\
\hline ACA & $1(5)$ & $1(10)$ & \\
\hline MCA & $4(20)$ & $0(0)$ & \\
\hline Posterior circulation & $6(30)$ & $3(30)$ & \\
\hline $\mathrm{BA}$ & $4(20)$ & $1(10)$ & \\
\hline PCOM & $1(5)$ & $1(10)$ & \\
\hline PCA & $0(0)$ & $1(10)$ & \\
\hline PICA & $1(5)$ & $0(0)$ & \\
\hline
\end{tabular}

statistical significant difference. The patients were followed up for a mean of 31 days (range between 26 and 34 days). Also, 90\% $(n=9)$ of cases in hyperacute group achieved a good outcome (mRS $0-2)$ on late 30 days follow-up, while only $45 \%(n=9)$ of cases of subacute group achieved a good outcome with statistical significant difference between both groups $(P=0.024)$ (Table 2).

Rebleeding was present in $40 \%(n=8)$ of cases in subacute group only. Statistically significant decrease in incidence in clinical rebleeding detected by postoperative CT of the brain was observed in patients undergoing aneurysm treatment within $24 \mathrm{~h}$ ( 0 versus $40 \%, P=0.029$ ) (Table 3 ).

Time interval from presentation to treatment was significantly higher in subacute group compared to hyperacute group $(P=0.0001)$, wherein the subacute group, the mean time interval from presentation to treatment was 78.60 versus $10.0 \mathrm{~h}$ in the hyperacute group (Table 4).

TABLE 2 | Comparison between the two studied groups as regards outcome.

\begin{tabular}{lccc}
\hline & $\begin{array}{c}\text { Subacute group } \\
\text { (after 24 h, } \\
\text { 20 patients) }\end{array}$ & $\begin{array}{c}\text { Hyperacute group } \\
\text { (within 24 h, } \\
\mathbf{1 0} \text { patients) }\end{array}$ & $\boldsymbol{P}$ value \\
\hline $\begin{array}{l}\text { Early 24 h outcome } \\
\text { Better outcome }\end{array}$ & $6(30)$ & $8(80)$ & $0.019^{*}$ \\
Worse outcome or no & $14(70)$ & $2(20)$ & \\
change & & & $0.024^{*}$ \\
Late 30 days outcome & & & \\
Good outcome & $9(45)$ & $9(90)$ & \\
High morbidity & $10(50)$ & $1(10)$ & \\
\hline
\end{tabular}

${ }^{*} P$ value $\leq 0.05$

TABLE 3 | Comparison between the two studied groups as regards to the incidence of rebleeding.

\begin{tabular}{lccc}
\hline & $\begin{array}{c}\text { Subacute group } \\
\text { (after 24 h, } \\
\text { 10 patients) }\end{array}$ & $\begin{array}{c}\text { Hyperacute group } \\
\text { (within 24 h, } \\
\text { 10 patients) }\end{array}$ & P value \\
\hline Symptomatic rebleeding & $8(40)$ & $0(0)$ & $0.029^{*}$ \\
${ }^{*} P \leq 0.05$. & & &
\end{tabular}

TABLE 4 | Comparison between the two studied groups as regards to time interval from presentation to treatment.

\begin{tabular}{|c|c|c|c|c|}
\hline & $\begin{array}{c}\text { Subacute group } \\
\text { (after } 24 \mathrm{~h}, \\
10 \text { patients) }\end{array}$ & $\begin{array}{l}\text { Hyperacute group } \\
\text { (within } 24 \mathrm{~h}, \\
10 \text { patients) }\end{array}$ & $t$ & $P$ value \\
\hline \multicolumn{5}{|c|}{$\begin{array}{l}\text { Time interval from } \\
\text { presentation to } \\
\text { treatment (hours) }\end{array}$} \\
\hline Min-max & 36.0-130.0 & $32.0-110.0$ & & \\
\hline Mean \pm SD & $78.60 \pm 25.057$ & $10.60 \pm 3.373$ & 11.923 & $0.0001^{*}$ \\
\hline Median & 80.0 & 10.0 & & \\
\hline
\end{tabular}




\section{DISCUSSION}

The time interval from presentation to management of acutely ruptured aneurysms (endovascular coiling) has been the issue of considerable debate (2). Definitions have been developed for specific time intervals that have been considered better or worse options during the last half century. Late treatment usually points to 10 days post-SAH; intermediate treatment points to days 4-10; early treatment points to the first 3 days; and ultra-early treatment points to surgery during the first $24 \mathrm{~h}$. We point to all treatment after the first $24 \mathrm{~h}$ as delayed, a group that included the previously mentioned early, intermediate, and late treatment (9).

After the initial SAH, rebleeding is the major cause of morbidity and poor outcome $(10,11)$. Among aneurysms that rebleed, approximately $20 \%$ do so in the first 2 weeks, $30 \%$ by the end of the first month, and $40 \%$ by the end of 6 months. Beyond 6 months, rerupture occurs at a rate of approximately $3 \%$ per year (12). No infallible rules predict which patients will have recurrent hemorrhages (13). Most studies reporting outcomes associated with rebleeding within the first $24 \mathrm{~h}$ have demonstrated case-fatality rates approaching $65 \%$, some as high as $80 \%$, and incidences of $10 \%(3)$.

Securing the ruptured intracranial aneurysm within the first $24 \mathrm{~h}$ after SAH has showed reduction in the risk of rebleeding. Earlier coiling of the ruptured aneurysm also means that medical or endovascular management for vasospasm/delayed ischemic neurological deficits can be initiated instantly (14).

In our cohort, $80 \%(n=8)$ of cases of hyperacute group achieved a better outcome on early $24 \mathrm{~h}$ follow-up compared to $30 \%(n=6)$ of cases of subacute group with statistical significant difference between both groups $(P=0.019)$. Our findings were in consistence with a retrospective 11-year single-center study done by Phillips et al., who suggested that treatment within $24 \mathrm{~h}$ was related to a better neurological outcome (15). Our findings are also in consistence with Bergui and Bradac, who reviewed the outcome of 45 consecutive patients treated acutely by coiling after $\mathrm{SAH}$ and found that about half had a favorable outcome; a promising result in accordance with some surgical and endovascular reports proposing early aggressive treatment of an aneurysm causing SAH (16). These findings are also in agreement with a study done by Wong et al., who reported that treatment within $24 \mathrm{~h}$ is associated with better clinical outcomes of aneurysmal $\mathrm{SAH}$, as less clinical rebleeding happens. The same study reported that aneurysm treatment carried out within the $24 \mathrm{~h}$ may improve clinical outcome and halve the clinical rebleeding in poor-grade SAH patients (17).

In the present cohort, $90 \%(n=9)$ of cases in hyperacute group achieved a good outcome (mRS 0-2) on late 30 days follow-up, while only $45 \%(n=9)$ of cases in subacute group achieved a good outcome with statistical significant difference between both groups $(P=0.024)$. The mortality in our patients $(5 \%, n=1)$ was more or less similar to that of the patients in the ISAT study (8.1\%), this can be partially explained by the fact that the higher prevalence of patients with milder clinical presentation, WFNS grades ( 1 and 2), in both cohorts (70\% of patients in our study and $88 \%$ of patients in the ISAT study) (18).

Regarding low prevalence of grades 4 and $5(0 \%, n=1)$ in group of patients treated within $24 \mathrm{~h}$, which was due to small number enrolled during study period, we think that it is a good chance that shows the true real practice, where those higher grade patients with higher possibility of having ICH or IVH are preferred to be managed with open surgery to additionally evacuate ICH or to deploy shunting for CSF.

In our cohort, symptomatic rebleeding was present in $40 \%$ $(n=8)$ of cases in subacute group only, all of the rebleeding cases had hypertension while six out of eight had poor admission grade (WFNS grade 3 or 4 ), which can explain the occurrence of rebleeding among these cases. Statistically significant decrease in incidence of clinical rebleeding was observed in patients undergoing aneurysm treatment within $24 \mathrm{~h}$ ( 0 versus $40 \%, P=0.029)$. These findings could be explained by significant longer door to puncture time interval in subacute group when compared to hyperacute group ( $p=0.0001)$. In 2001, Ohkuma et al. (19) examined 273 patients who were admitted to their institution within $24 \mathrm{~h}$ after the initial SAH bleeding and recorded that $13.6 \%$ of patients with SAH suffered rebleeding in the ambulance or before admission to the referring hospital, which was related to systolic arterial pressure $>160 \mathrm{mmHg}$. Our result went also in agreement with Guo et al., who showed that rebleeding found in 24 patients (34.3\%) within $3 \mathrm{~h}$ compared to 44 patients (62.9\%) within $6 \mathrm{~h}$ with aneurysm size and systolic arterial pressure were the independent risk factors for aneurysmal rebleeding (20). In other study, Tanno et al. reported that rebleeding occurs more frequently in the earlier period after the initial SAH than previously believed and found that rebleeding occurred in 65 patients (35.9\%) within $3 \mathrm{~h}$ and 88 patients (48.6\%) within $6 \mathrm{~h}$ after the initial SAH, which was not related to hypertension, as systolic arterial blood pressure prior to rebleeding was most common between 120 and $140 \mathrm{mmHg}$ (4).

The primary limitation of this study is the way of enrollment of our cases, which was based on availability of cases and not on randomization. The present study was also limited by the small sample size that may be due to the narrow time frame of the study. This may shed light on the real practice behavior of referring such patients at least in our region that needs to be changed, so further study with larger sample size is required to confirm the findings.

\section{CONCLUSION}

Aneurysm treatment within $24 \mathrm{~h}$ may be associated with better clinical outcome. The study affirms evidence that management of ruptured intracranial aneurysms within $24 \mathrm{~h}$ of SAH is associated with better immediate and short-term clinical outcome.

\section{AUTHOR CONTRIBUTIONS}

All authors listed have made substantial, direct, and intellectual contribution to the work and approved it for publication. 


\section{REFERENCES}

1. Nieuwkamp DJ, Setz LE, Algra A, Linn FH, RooijNK, RinkelGJ. Changes in case fatality of aneurysmal subarachnoid haemorrhage over time, according to age, sex, and region: a meta-analysis. Lancet Neurol (2009) 8:635-42. doi:10.1016/ S1474-4422(09)70126-7

2. Cha K, Kim J, Kang H, Moon B, Lee S, Kim J. Aneurysmal rebleeding: factors associated with clinical outcome in the rebleeding patients. J Korean Neurosurg Soc (2010) 47:119. doi:10.3340/jkns.2010.47.2.119

3. Rosenorn J, Eskesen V, Schmidt K, Ronde F. The risk of rebleeding from ruptured intracranial aneurysms. J Neurosurg (2009) 67:329-32. doi:10.3171/ jns.1987.67.3.0329

4. Tanno Y, Homma M, Oinuma M, Kodama N, Ymamoto T. Rebleeding from ruptured intracranial aneurysms in north eastern province of Japan. A cooperative study. J Neurol Sci (2007) 258:11-6. doi:10.1016/j.jns.2007.01.074

5. Laidlaw J, Siu K. Ultra-early surgery for aneurysmal subarachnoid hemorrhage: outcomes for a consecutive series of 391 patients not selected by grade or age. J Neurosurg (2002) 97:250-8. doi:10.3171/jns.2002.97.2.0250

6. Lawson MF, Chi Y-Y, Velat GJ, Mocco JD, Hoh BL. Timing of aneurysm surgery: the international cooperative study revisited in the era of endovascular coiling. J Neurointerv Surg (2010) 2:131-4. doi:10.1136/jnis.2009. 001172

7. Teasdale GM, Drake CG, Hunt W, Kassell N, Sano K, Pertuiset B, et al. A universal subarachnoid hemorrhage scale: report of a committee of the World Federation of Neurosurgical Societies. J Neurol Neurosurg Psychiatry (1988) 51(11):1457. doi:10.1136/jnnp.51.11.1457

8. van Swieten JC, Koudstaal PJ, Visser MC, Schouten HJ, van Gijn J. Interobserver agreement for the assessment of handicap in stroke patients. Stroke (1988) 19:604-7. doi:10.1161/01.STR.19.5.604

9. Jagt MVD, Hasan D, Dippel DWJ, Dijk EJV, Avezaat CJJ, Koudstaal PJ. Impact of early surgery after aneurysmal subarachnoid haemorrhage. Acta Neurol Scand (2009) 119:100-6. doi:10.1111/j.1600-0404.2008.01064.x

10. Bederson JB, Connolly ES Jr, Batjer HH, Dacey RG, Dion JE, Diringer MN, et al. Guidelines for the management of aneurismal subarachnoid hemorrhage: a statement for healthcare professionals from a special writing group of the stroke council, American Heart Association. Stroke (2009) 40(3):994-1025. doi:10.1161/STROKEAHA.108.191395

11. Weyer GW, Nolan CP, Macdonald RL. Evidence-based cerebral vasospasm management. Neurosurg Focus (2006) 21:8. doi:10.3171/foc.2006. 21.3.8
12. Parkarinen S. Incidence, etiology, and prognosis of primary subarachnoid hemorrhage: a study based on 589 cases diagnosed in a defined urban population during a defined period. Acta Neurol Scand (1967) 43(29):1-128.

13. Locksley HB. Report of the cooperative study of intracranial aneurysms and subarachnoid hemorrhage. Sec V, part I: natural history of subarachnoid hemorrhage, intracranial aneurysms, and arteriovenous malformation-based on 6,368 cases in the cooperative study. J Neurosurg (1966) 25:219-39. doi:10.3171/jns.1966.25.2.0219

14. Eddleman CS, Hurley MC, Naidech AM, Batjer HH, Bendok BR. Endovascular options in the treatment of delayed ischemic neurological deficits due to cerebral vasospasm. Neurosurg Focus (2009) 26:E6. doi:10.3171/2008.11. FOCUS08278

15. Phillips TJ, Dowling RJ, Yan B, Laidlaw JD, Mitchell PJ. Does treatment of ruptured intracranial aneurysms within 24 hours improve clinical outcome. Stroke (2011) 42:1936-45. doi:10.1161/STROKEAHA.110.602888

16. Bergui M, Bradac GB. Acute endovascular treatment of ruptured aneurysms in poor-grade patients. Neuroradiology (2004) 46(2):161-4. doi:10.1007/ s00234-003-1143-5

17. Wong GK, Boet R, Ng SC, Chan M, Gin T, Zee B, et al. Ultra-early (within 24 hours) aneurysm treatment after subarachnoid hemorrhage. World Neurosurg (2012) 77(2):311-5. doi:10.1016/j.wneu.2011.09.025

18. Britz GW. ISAT trial: coiling or clipping for intracranial aneurysms? Lancet (2005) 366:783-5. doi:10.1016/S0140-6736(05)67190-5

19. Ohkuma H, Tsurutani H, Suzuki S. Incidence and significance of early aneurysmal rebleeding before neurosurgical or neurological management. Stroke (2001) 32:1176-80. doi:10.1161/01.STR.32.5.1176

20. Guo LM, Zhou HY, Xu JW, Wang Y, Qiu YM, Jiang JY. Risk factors related to aneurysmal rebleeding. World Neurosurg (2011) 76(3-4):292-8. doi:10.1016/j. wneu.2011.03.025

Conflict of Interest Statement: The authors declare that the research was conducted in the absence of any commercial or financial relationships that could be construed as a potential conflict of interest.

Copyright (C) 2016 Ibrahim Ali, Ashmawy, Eassa and Mansour. This is an open-access article distributed under the terms of the Creative Commons Attribution License (CC $B Y)$. The use, distribution or reproduction in other forums is permitted, provided the original author(s) or licensor are credited and that the original publication in this journal is cited, in accordance with accepted academic practice. No use, distribution or reproduction is permitted which does not comply with these terms. 